Check for updates

Cite this: New J. Chem., 2017, 41,5713

Received 10th April 2017 Accepted 22nd May 2017 DOI: 10.1039/c7nj01191a rsc.li/njc

\section{Highly selective voltammetric sensing of paracetamol on nanogold modified electrode in the presence of interfering compounds}

\begin{abstract}
Teresa Łuczak iD
A gold bare template modified with gold nanoparticles deposited on top self-assembled layers (SAMs) results in a high catalytic effect for paracetamol electrooxidation both when paracetamol is alone in solution at $\mathrm{pH} 7$ and in a ternary mixture containing the biogenic interfering compounds ascorbic acid and uric acid. For this novel sensor a linear relationship is found between the current response of paracetamol at the potential of peak maximum $\left(j_{\mathrm{p}}\right)$ and the concentration of this compound in solution $\left(c_{\text {ACAP }}\right)$ over the range of $0.0001 \mathrm{mM}$ to $2 \mathrm{mM}$ with the detection limit of $0.018 \mu \mathrm{M}$. Moreover, the peak to peak separations of the voltammetric responses obtained on the modified electrode confirm that the newly prepared modified gold electrode appears to be a good candidate for the selective detection and analytical determination of paracetamol, ascorbic acid and uric acid in ternary mixtures.
\end{abstract}

\section{Introduction}

Paracetamol [(acetaminophen), ACAP] belongs to a therapeutic class of analgesics that simultaneously act as antipyretic and anti-inflammatory drugs. It is an alternative medicament for people who cannot take aspirin. ACAP has an excellent safety profile when it is applied in proper therapeutic doses. This drug is popular, commonly available and moreover increasingly used. For these reasons it may be easily overdosed, which could make a very serious problem for human health and even life since it may lead to liver and kidney damage. ${ }^{1,2}$ Therefore, the development of a simple, fast and sensitive method for ACAP detection and determination is an important task from both fundamental and practical points of view in bioscience as well as in medicinal chemistry and has been the subject of an increased number of papers published in the last few years. The literature provides several methods for ACAP determination using spectroscopic, ${ }^{3-6}$ flow-injection ${ }^{7,8}$ and chromatographic ${ }^{9,10}$ methods. However, to date, the most promising methods for ACAP detection and determination seems to be electrochemical sensing techniques. These techniques are extremely rapid, accurate and, above all, do not require the use of toxic solvents. In most electrochemical studies reported, carbon based modified electrodes have been explored. For example, functionalised multiwalled carbon nanotubes (MWCNT) $)^{11-17}$ or graphene ${ }^{18-20}$ have been used as agents to modify the carbon electrode. Moreover, studies on glassy carbon electrodes modified with poly(caffeic acid), ${ }^{21}$

Faculty of Chemistry, Adam Mickiewicz University in Poznań, Umultowska 89 b, 61614 Poznań, Poland.E-mail: telucz@amu.edu.pl polyfuran ${ }^{22}$ and polycalconcarboxylic acid ${ }^{23}$ films have been reported. In addition to the different carbon materials used as a template for preparing modified electrodes, the promotion of electron transfer in the electrochemical reaction during ACAP electrooxidation was achieved after the application of gold electrodes covered with polypyrole doped with aszoophloxine. ${ }^{24}$ Moreover a catalytic oxidation effect was observed during ACAP oxidation on a carbon paste electrode modified with gold nanoparticles. ${ }^{25}$

Since human body fluids contain a large amount of biogenic compounds, among which ascorbic and uric acids reach the highest concentrations, ${ }^{1}$ the determination of any substance without taking into account the effect of ascorbic acid (AA) and uric acid (UA) is inaccurate. The effect of AA on ACAP detection at carbon modified electrodes has been considered elsewhere. ${ }^{25,26}$ Although a large number of experimental data are available, the development of novel and easy to synthesize materials capable of simultaneous detection of ACAP in the presence of biogenic molecules is still a challenging task for electrochemists. Knowing that the use of nanoparticles of noble metals can bring a catalytic effect for this process much higher than that on an unmodified electrode, ${ }^{27-29}$ the aim of this study is to obtain a gold electrode modified with dihydrolipoic acid (DHLA), cysteamine (CA) and gold nanoparticle (NPs-Au) layers and test is electrode electroactivity towards the electrooxidation of ACAP alone in a solution of $\mathrm{pH} 7$ and in a mixture with interfering AA and UA. To date, the literature has not provided evidence of electrocatalytic oxidation and detection of ACAP on materials composed of dihydrolipoic acid, cysteamine and gold nanoparticles. 


\section{Experimental}

\section{Reagents and solutions}

The following chemicals of the purity given in brackets were used: $\mathrm{NaH}_{2} \mathrm{PO}_{4}(99.99 \%)$ and $\mathrm{K}_{2} \mathrm{HPO}_{4}(99.99 \%), \mathrm{NaOH}(99 \%)$, trisodium citrate (99\%), $\mathrm{H}_{2} \mathrm{SO}_{4}\left(96 \%\right.$ extra pure), $30 \% \mathrm{H}_{2} \mathrm{O}_{2}$ (min. 29\%, max. 33\%), acetone (99.50\%), and $\mathrm{C}_{2} \mathrm{H}_{5} \mathrm{OH}(99.9 \%)$ were purchased from POCh (Gliwice, Poland). Auric acid $\left(\mathrm{HAuCl}_{4}\right)$ (99.999\%), ( \pm )dihydrolipoic acid (99.9\%), cysteamine ( $\geq 99 \%)$, acetaminophen $(\geq 99 \%) \quad$ [Synonyms: 4 '-hydroxyacetanilide, 4-acetamidophenol, $N$-(4-hydroxyphenyl)acetamide, $N$-acetyl-4aminophenol, APAP, paracetamol], ascorbic acid (99.9\%) and uric acid (99.9\%) were obtained from Sigma-Aldrich. Panadol tablets (containing $500 \mathrm{mg}$ of ACAP per tablet) were from GLAXOSMITHKLINE. All solutions were prepared using Millipore Milli-Q-water, and solvents and chemicals were used as received without further purification. All solutions investigated were deaerated by high purity argon (99.998\%) before measurements at room temperature.

A gold colloidal solution (Au sol) was prepared according to the procedure given in ref. $30.0 .75 \mathrm{~cm}^{3}$ of $0.60 \% \mathrm{HAuCl}_{4}$ was added to $50 \mathrm{~cm}^{3}$ of water and heated until boiling. Then, $2.5 \mathrm{~cm}^{3}$ of $1 \%$ trisodium citrate was added to the boiling solution with stirring. A typical red wine color was observed after a few minutes. The gold sol was stored in a dark glass at $4{ }^{\circ} \mathrm{C}$.

Samples with mixtures of ACAP, AA and UA were prepared as follows: 1 tablet of Panadol (containing $500 \mathrm{mg}$ of ACAP) was diluted to $0.05 \mathrm{dm}^{3}$ with $60 \mathrm{mM}$ phosphate buffer solution, $\mathrm{pH}$ 7. Then, $0.1 \mathrm{~cm}^{3}$ of this solution, $10 \mathrm{~cm}^{3}$ of a standard solution of ascorbic acid (50 mM) and $10 \mathrm{~cm}^{3}$ of a standard solution of uric acid ( $50 \mathrm{mM})$ were added to a $100 \mathrm{~cm}^{3}$ volumetric flask and filled up to the mark with $60 \mathrm{mM}$ phosphate buffer solution, $\mathrm{pH}$ 7. In the prepared mixture the concentrations of ACAP, AA and UA were $0.066 \mathrm{mM}, 5 \mathrm{mM}$ and $5 \mathrm{mM}$, respectively.

\section{Instrumentation}

Electrochemical measurements were carried out in a conventional three compartment cell separated by glass frits using an Autolab potentiostat/galvanostat analyzer (AUTOLAB PGSTAT 302N, Eco Chemie, B. V., Utrecht, The Netherlands). The pH of the solutions was measured using a pH-meter (Model-ULAB 2002, TELE-ECO-PROJECT, Poland). UV-Vis spectra were obtained using a Cecil instrument (CE 2020, Chemnist, Austria). Reflectionabsorption spectra were obtained in a nitrogen atmosphere on a Bruker 66 v/S FT-IR spectrometer with an FT-80 grazing angle infrared reflection accessory and a liquid $\mathrm{N}_{2}$ cooled TGS detector. Typically, 2000 scans with $2 \mathrm{~cm}^{-1}$ resolution were taken. Additionally, for comparison the transmission FT-IR spectrum of the respective substrate was recorded on the same spectrometer. Scanning electron microscopy (SEM) analysis was carried out using a ZEISS EVO 40 instrument (Germany) at an acceleration voltage of $20 \mathrm{kV}$. Transmission electron microscopy (TEM) images were obtained using a JEM-1200 EX2 (Japan) instrument operating at $200 \mathrm{kV}$ after drying the gold colloidal solution covered with foil strengthened with carbon.

\section{Electrodes}

The working electrode of $0.07 \mathrm{~cm}^{2}$ geometric area was either the bare gold electrode (labeled as Au electrode) or the gold electrode modified (labeled as Au/NPs-Au electrode) as described below. A gold sheet was used as an auxiliary electrode $\left(2 \mathrm{~cm}^{2}\right)$ and a saturated calomel electrode (SCE) served as the reference electrode.

\section{Electrode activation}

Before the experiment, the bare gold electrode was polished with aluminum slurries of successively decreasing final grades down to $0.05 \mu \mathrm{m}$ (Buehler) on polishing cloths (Buehler) and subsequently rinsed with water, acetone and water again. After that the electrode was electrochemically activated in the supporting electrolyte solution (phosphate buffer, $60 \mathrm{mM}$, $\mathrm{pH} 7)$ by scanning the electrode potential $\left(v=\mathrm{d} E / \mathrm{d} t=0.1 \mathrm{~V} \mathrm{~s}^{-1}\right)$ in the potential range between $E=-1.0 \mathrm{~V}$ and $E=1.0 \mathrm{~V}$ versus SCE (that is between the onset of hydrogen and oxygen evolution, respectively) until a stable cyclic voltammogram (acronyms CV or $j-E$ curve) was obtained.

In the case of the modified electrodes, at the end of all series of measurements, in order to recover the Au bare electrode, the self-assembled layers were removed from the modified gold template by dipping it for about 5 minutes in Piranha solution, i.e. in a mixture of aqueous solutions of $96 \% \mathrm{H}_{2} \mathrm{SO}_{4}$ and $30 \% \mathrm{H}_{2} \mathrm{O}_{2}$ at the volume ratio $3: 1$. Subsequently, the above described procedure of polishing, activation and modification of the bare gold electrode was repeated.

\section{Electrode modification}

The modification of the bare gold electrode was carried out in 3 steps. The time of immersion of a given modified template in an appropriate modifying agent in each step was established in preliminary studies.

In the first step, a self-assembled layer (SAM) of dihydrolipoic acid was prepared by immersion of the activated Au template in a $10 \mathrm{mM}$ ethanolic solution of this acid, for $4 \mathrm{~h}$. The obtained modified template (Au/DHLA electrode) was washed with water, acetone and water again and dried in an argon stream. In the second step of modification, the Au/DHLA template was immersed in a $0.2 \mathrm{mM}$ solution of cysteamine for $2 \mathrm{~h}$. The obtained $\mathrm{Au} / \mathrm{DHLA} / \mathrm{CA}$ template (Au/DHLA/CA electrode) was washed and dried in the same way as the first step. In the third step of modification, in order to immobilize the gold nanoparticles, the earlier obtained Au/DHLA/CA SAM template was dipped in a gold sol solution at $4{ }^{\circ} \mathrm{C}$ for $24 \mathrm{~h}$. Subsequently, the procedure of washing and drying was repeated. The Au/DHLA/CA/NPs-Au electrode prepared according to the above described three-stage process was ready to use in electrochemical measurements. The following electrodes were obtained according to the following scheme:

$\mathrm{Au} /$ DHLA electrode: [Au $\rightarrow$ DHLA acid $(4 \mathrm{~h})$ ];

$\mathrm{Au} /$ DHLA/CA electrode: [Au $\rightarrow$ DHLA acid $(4 \mathrm{~h}) \rightarrow \mathrm{CA}$ (2 h)] and

Au/DHLA/CA/NPs-Au electrode: $[\mathrm{Au} \rightarrow$ DHLA acid $(4 \mathrm{~h}) \rightarrow$ CA $(2 \mathrm{~h}) \rightarrow \operatorname{sol} \mathrm{Au}(24 \mathrm{~h})]$. 
Preliminary studies showed, that from these 3 modified electrodes, the highest catalytic effect was obtained for the $\mathrm{Au} / \mathrm{DHLA} / \mathrm{CA} / \mathrm{NPs}-\mathrm{Au}$ electrode (labeled as the Au/NPs-Au electrode) and therefore, in the next section, only the results obtained for the Au/NPs-Au electrode are presented.

\section{Repeatability and stability of modified electrode}

To characterize the repeatability of the prepared modified gold electrode, repetitive measurements were carried out in supporting electrolyte solution (phosphate buffer, $60 \mathrm{mM}, \mathrm{pH}$ 7) containing $0.5 \mathrm{mM}$ ACAP. The R.S.D. (\%) of the voltammetric responses for 10 successive determinations on the Au/NPs-Au electrode was $2 \%$. Moreover, the stability of the modified electrode was verified by measuring its voltammetric response in the supporting electrolyte solution containing $0.5 \mathrm{mM}$ ACAP everyday for one month. After each daily stability test, the electrode was washed with water, dried in an argon stream and stored in open circuit in tubes without solution. In 4 weeks, the voltammetric response for the $0.5 \mathrm{mM}$ ACAP oxidation decreased by about $4 \%$ of the initial response for the prepared $\mathrm{Au} / \mathrm{NPs}-\mathrm{Au}$ electrode. The above facts indicate that both the prepared modified electrode and the proposed method for the determination of ACAP have a good reproducibility and stability.

\section{Results and discussion}

\section{The gold modified electrode surface}

Self-assembling layers on metal surfaces may be formed in two ways. ${ }^{28,31,32}$ The first way involves attachment of the modifying compounds to a modified template by direct immersion of the template into a solution with the modifying compound. In this case, no binding molecules are used, and the SAM layer is formed via electrostatic, hydrogen or van der Waals interactions. The second way involves the use of modifying agents, which are compounds with atoms characterized by high affinity to the surface atoms of the modified template. When the atoms of the modifying compounds come in contact with the surface atoms of the modified template, strong covalent bonds are developed between them. Admittedly, the second method has an advantage over the first because the strength of the covalent bond exceeds the strength of the other above mentioned types of interactions. $^{33-35}$

The gold sol used in this work, which was obtained by the method described in ref. 30, contains gold nanoparticles with an average diameter of about $16 \mathrm{~nm}$, as evaluated from the transmission electron microscopy image (TEM) in Fig. 1a.

The UV-Vis spectrum of this sol shows only one band with a maximum at $\lambda_{\text {max }}=530 \mathrm{~nm}$. In the sol prepared no aggregation of gold nanoparticles occurs, which is confirmed by the absence of a band at around $\lambda=680 \mathrm{~nm}$ in its spectrum (see inset in Fig. 1a). This is in agreement with the earlier studies. ${ }^{35-38}$ In the present study, in order to obtain an SAM covered electrode surface, the gold template was modified with NPs-Au and both DHLA and CA, where the two latter compounds serve as binding molecules. $^{33-35}$ The choice of DHLA was dictated by a the

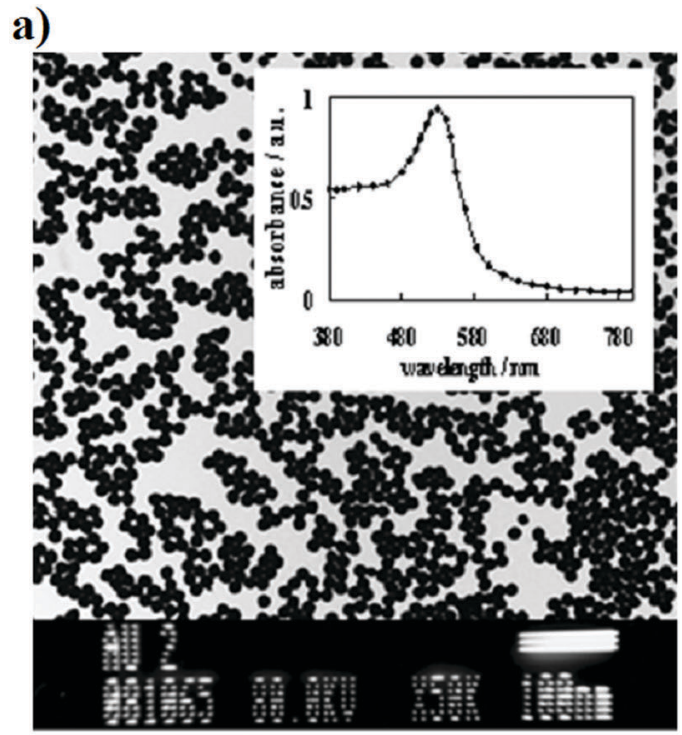

b)

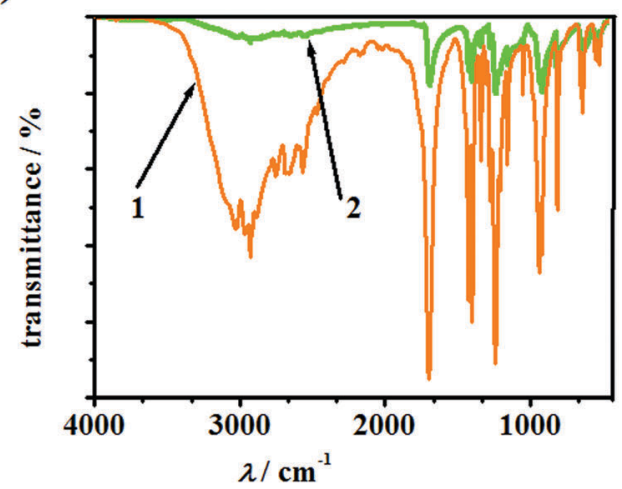

Fig. 1 Characterisation of the gold template modifying agent: (a) transmission electron image of the gold nanoparticles. Scale bar: $100 \mathrm{~nm}$. Inset: Optical UV-Vis spectrum of the colloidal gold solution. (b) Transmission FT-IR spectrum (1) and reflectance spectrum of dihydrolipoic acid adsorbed on the gold plate (2).

stronger affinity of this compound towards gold and higher extent of dissociation of its carboxyl groups ${ }^{39}$ as compared to that of the previously studied S-containing alkane acids. ${ }^{35,40}$ Fig. 1b compares the transmission FT-IR spectrum of the liquid DHLA (spectrum 1) with the infrared reflection spectrum of the Au surface with adsorbed molecules of this acid (spectrum 2). The FT-IR spectra clearly indicate the formation of the adsorbate on the Au surface due to the fact that band in the region of $2600-2550 \mathrm{~cm}^{-1}$ assigned to the $\mathrm{S}-\mathrm{H}$ stretching vibrations modes disappears. The absence of this band in spectrum 2 proves that during the formation of the adsorbate since the $\mathrm{S}-\mathrm{H}$ bands are broken and the $\mathrm{S}$ atoms are directly bonded with the Au surface atoms. This is in accordance with the previously reported information on proton abstraction from alkanethiols adsorbed on a gold surface. ${ }^{33,41-43}$

As described in the Experimental section, the basic strategy for the preparation of the SAM layers on the Au template was divided into 3 steps, as illustrated in Scheme 1.

In the first stage of modification of the bare $\mathrm{Au}$ electrode, the firm attachment of DHLA to the gold electrode surface is 


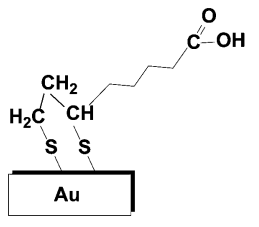

$1^{\text {st }}$ stage:

Au in the DHLA solution, time 4h

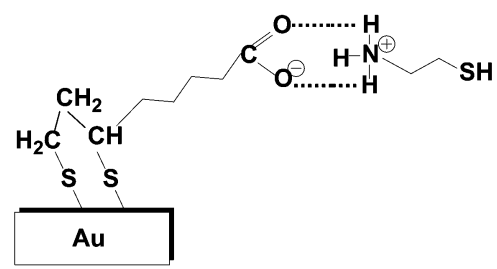

$2^{\text {nd }}$ stage:

Au/DHLA in the CA solution, time $2 \mathrm{~h}$

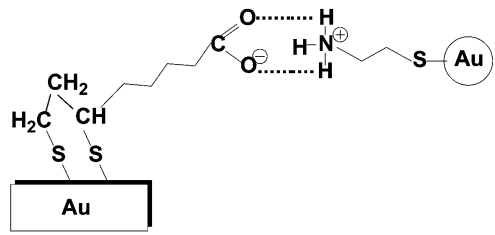

$3^{\text {rd }}$ stage:

Au/DHLA/CA in the gold sol, time $24 \mathrm{~h}$

Scheme 1 Successive stages of the bare gold template modification.

realized by the formation of two covalent bonds between the $\mathrm{Au}$ and $\mathrm{S}$ atoms after the $\mathrm{S}-\mathrm{H}$ bonds are split in the DHLA molecule. It is generally accepted that chemisorption of $\mathrm{S}$ functionalized compounds on gold is preceded by the oxidative abstraction of hydrogen, which in our case is from $\mathrm{S}-\mathrm{H}$ bonds, whereas the rest of the modifying molecules create an ordered structure at the electrode which is tilted at angle towards the electrolyte solution. ${ }^{33,44}$ In the second step of modification, when the Au template covered by an SAM layer of DHLA comes into contact with a solution of $\mathrm{CA}$, the $\mathrm{COOH}$ terminated group localized at the end of DHLA layers attached to the gold surface atoms can be easily bonded to the amine group of CA. Comparison of the $\mathrm{p} K_{\mathrm{a}}$ values of DHLA and CA shows that the carboxylic groups of DHLA $\left(\mathrm{p} K_{\mathrm{a}}=4.90\right)^{45}$ are mostly dissociated at $\mathrm{pH}=7$ of the electrolyte solution and the $\mathrm{COO}^{-}$terminated negatively charged layers of DHLA may favorably interact with the positively charged part (i.e. with the protonated $\mathrm{NH}_{3}{ }^{+}$ group) of CA ( $\mathrm{p} K_{\mathrm{a}}=8.35$ and $\left.\mathrm{p} K_{\mathrm{a}}=10.81\right) .{ }^{45}$ Moreover, strong hydrogen bonds can be formed between the carboxylic groups of DHLA and the $\mathrm{NH}_{2}$ group of CA. ${ }^{39}$ This explains the formation of a stable DHLA-CA complex with the $\mathrm{SH}$ group of CA exposed towards the top-side of the expanded monolayer. After the second stage, the obtained Au/DHLA/CA template may be subject to further modification with NPs-Au. The formation of covalent bonds occurs between the S atoms of CA and NPs-Au nanoparticles, as shown in Scheme 1. With the three stages, described above, it was possible to obtain the Au/DHLA/CA/Au-NPs modified electrode with NPs-Au attached on the top of the SAM layer, as shown in Scheme 1.

Fig. 2a compares the stable cyclic voltammograms of the bare polycrystalline gold electrode (marked as the Au electrode) with that obtained after modification with DHLA, CA and NPs-Au (marked as the Au/NPs-Au electrode) recorded (after the $2^{\text {nd }}$ scan) in the supporting electrolyte solution, $60 \mathrm{mM}$ phosphate buffer, $\mathrm{pH}$ 7. As follows from Fig. $2 \mathrm{a}$ in a wide range of potential ( $E=-0.95 \mathrm{~V}$ and $E=0.6 \mathrm{~V}$ versus $\mathrm{SCE}$ ) no faradic processes occur on the electrode surface, only charging/discharging of the double layer takes place. It should be noted that due to the method used for the gold template activation, we did not observe any signals in the $j-E$ curves that may be connected with the gold surface reconstruction process, as described elsewhere. ${ }^{46}$ The welldefined anodic peaks at $E=0.70 \mathrm{~V}$ versus SCE and $E=0.65 \mathrm{~V}$ versus SCE, and moreover, cathodic contra-peaks at $E=0.65 \mathrm{~V}$ versus SCE and $E=0.55 \mathrm{~V}$ versus SCE visible in the $j-E$ curves, recorded in the supporting electrolyte solution using $\mathrm{Au}$ and $\mathrm{Au} / \mathrm{NPs}-\mathrm{Au}$ electrodes, are assigned to the formation of gold oxide and its reduction, respectively. ${ }^{47}$ There is no doubt that the real surface area of the electrode after the modification process increased. ${ }^{48}$

\section{a)}

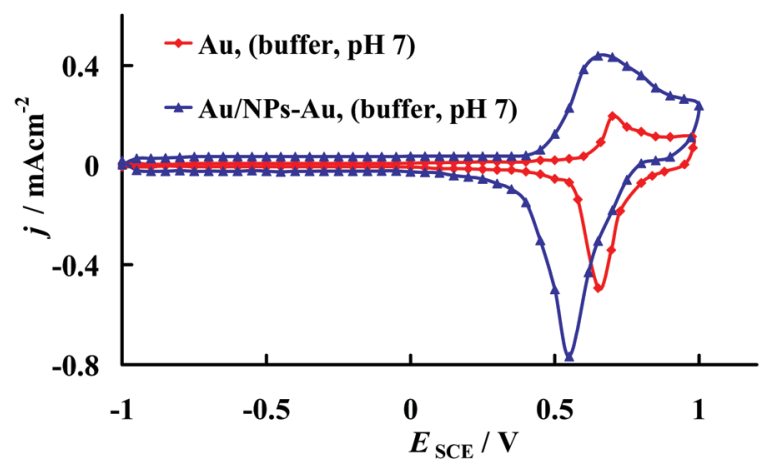

b)

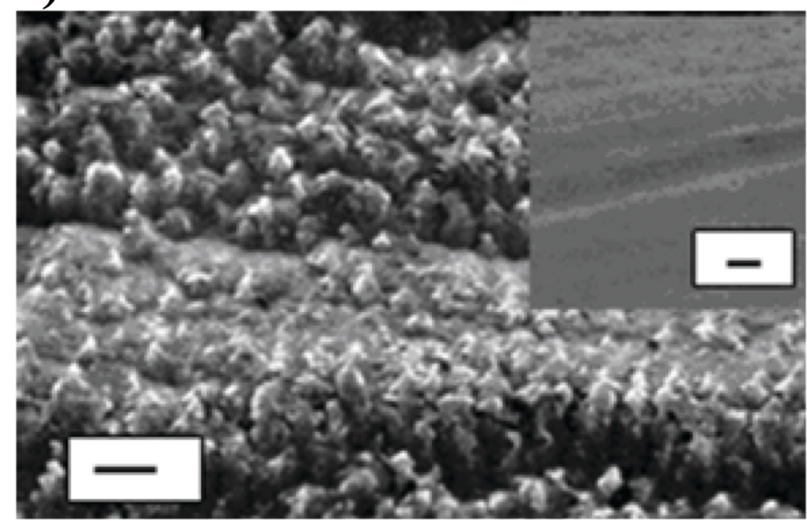

Fig. 2 (a) CVs of the Au and Au/NPs-Au electrodes in $60 \mathrm{mM}$ phosphate buffer, $\mathrm{pH} 7, v=0.1 \mathrm{~V} \mathrm{~s}^{-1}$. (b) Scanning electron micrographs of the modified Au/NPs-Au surface. Inset: Scanning electron micrographs of the bare Au surface. Scale bar: $2 \mu \mathrm{m}$. Magnification: $10000 \times$ and accelerating voltage: $20 \mathrm{kV}$. 
As a result of the gold electrode modification, the roughness factor $(r f)$, which is calculated as the ratio of the real surface area of the electrode to its geometrical area, changed. The roughness factors of the electrodes used were estimated assuming that the charge of $0.400 \mathrm{mC} \mathrm{cm}^{-2}$ is required for the reduction of a monolayer of oxygen chemisorbed onto a given gold surface during the positive going potential sweep up to the potential of the beginning of oxygen evolution. ${ }^{49}$ The roughness factors of the used modified and unmodified gold electrodes were estimated to be 3.2 and 1.5, respectively. Taking into account these values, it was found that the real surface area of the modified gold electrode prepared in this work was about 2.2 times greater than that of the unmodified gold electrode. An increase in the roughness factor due to modification of gold template is well visible in SEM images presented in Fig. 2b.

\section{Oxidation of paracetamol at the bare and modified gold electrodes}

The electrochemical oxidation of ACAP in aqueous solution occurs according to the mechanism adopted in the literature ${ }^{50}$ which is presented in Scheme 2. According to this mechanism, ACAP is oxidized to the quinone derivative (ACAP-quinone) after the exchange of 2 electrons and 2 protons.

Fig. 3a and b present the cyclic voltammetric responses in the presence of $0.5 \mathrm{mM}$ of ACAP at the bare gold electrode $(\mathrm{Au})$ and at the modified gold electrode (Au/NPs-NPs), respectively. For comparison, in Fig. $3 \mathrm{a}$ and b, the CVs recorded at a given electrode in pure supporting electrolyte solution are included. Moreover, for clarity Fig. 3c compares the CVs recorded for $0.5 \mathrm{mM}$ ACAP at the electrodes studied in the same experimental conditions.

The evolution of the current densities after successive cycles may be useful to give information about the poisoning of the surface, but in this study the current densities were not altered after successive scans, so the fouling effect of the electrode surfaces was not observed during ACAP electrooxidation. According to Fig. 3a, at the gold electrode, the anodic peak with the maximum at $E=0.6 \mathrm{~V}$ versus SCE and with the peak current density $j_{\mathrm{p}}=0.367 \mathrm{~mA} \mathrm{~cm} \mathrm{~cm}^{-2}$ as well as the cathodic peak with the maximum at $E=0.35 \mathrm{~V}$ versus SCE and with the peak current density $j_{\mathrm{p}}=-0.154 \mathrm{~mA} \mathrm{~cm}{ }^{-2}$ are assigned to the quasi-reversible ACAP oxidation to ACAP-quinone. Meanwhile, under the same experimental conditions, for ACPA oxidation at the modified gold electrode, in Fig. $3 \mathrm{~b}$ the anodic peak reaches the maximum current density at $E=0.237 \mathrm{~V}$ versus SCE with $j_{\mathrm{p}}=1.295 \mathrm{~mA} \mathrm{~cm}{ }^{-2}$, whereas the cathodic peak appears at $E=0.127 \mathrm{~V}$ versus SCE and the current density obtained in this

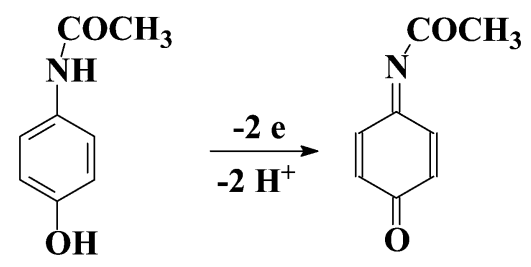

Scheme 2 Electrochemical oxidation of ACAP. a)

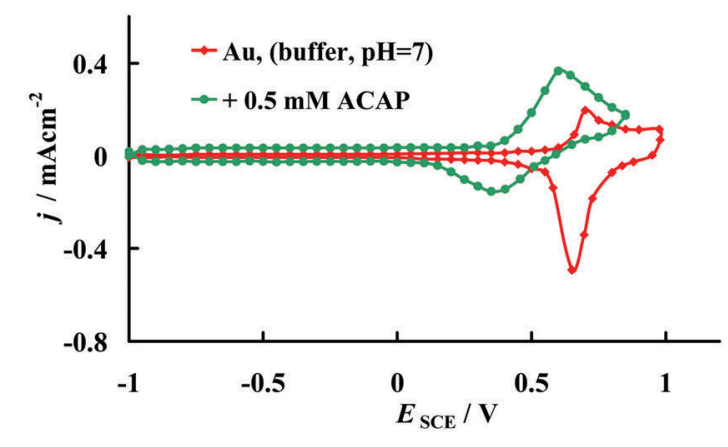

b)

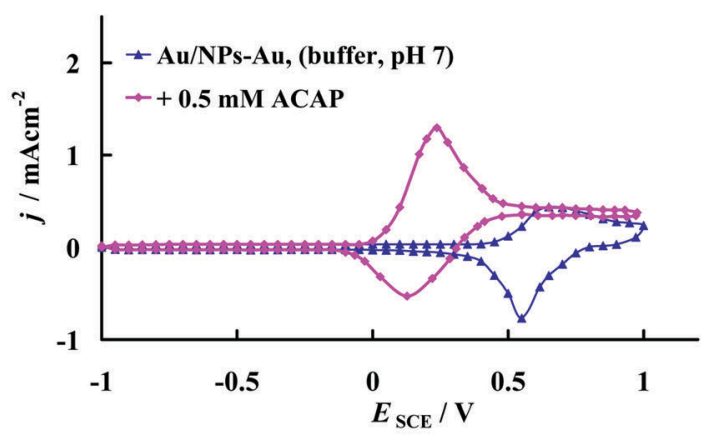

c)

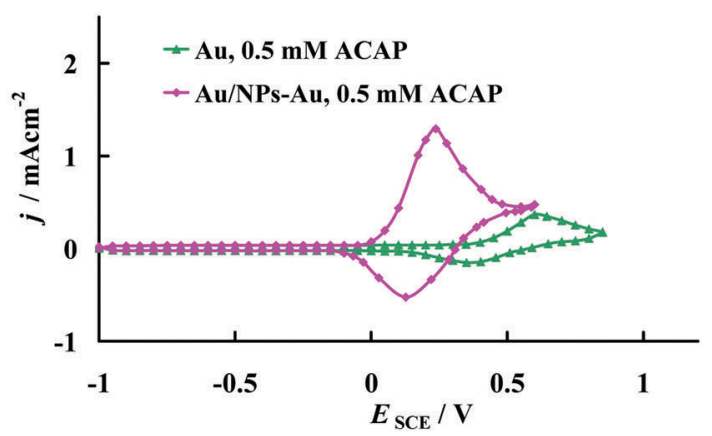

Fig. $3 \mathrm{CVs}$ recorded in $60 \mathrm{mM}$ phosphate buffer, $\mathrm{pH} 7$ alone and with $0.5 \mathrm{mM}$ ACAP at the (a) Au and (b) Au/NPs-Au electrodes. (c) Comparison of the CVs recorded for $0.5 \mathrm{mM} \mathrm{ACAP}$ at the Au and Au/NPs-Au electrodes in $60 \mathrm{mM}$ phosphate buffer, $\mathrm{pH} 7, v=0.1 \mathrm{~V} \mathrm{~s}^{-1}$.

peak reaches $j_{\mathrm{p}}=-0.528 \mathrm{~mA} \mathrm{~cm} \mathrm{co}^{-2}$. The following analysis of the experimental data will only be for the anodic peak.

According to the electrochemical kinetics theory, in evaluation of the catalytic effect two factors should be considered, the decrease in the overpotential of oxidation and increase in the current density. These phenomena lead to an improvement in the electrocatalytic effect on the kinetics of the electrode reactions. ${ }^{48}$ The results presented in Fig. 3 prove that the electrode material prepared in this work contributes to achieving a high catalytic effect during ACAP oxidation. This is manifested as a substantial shift in the voltammetric peaks towards the negative potential accompanied by an increase in the current response at the peak maxima in comparison with that characteristic 
of the bare gold electrode. Taking into consideration the quotient of the current density value observed in the anodic peak, $j_{\mathrm{p}}$ and the roughness factor of the modified and unmodified electrodes $(3.2 / 1.5=2.2)$, it was expected that the current density for ACAP electrooxidation on the Au/NPs-Au electrode should be 2.2 times higher than that obtained on the bare $\mathrm{Au}$ (it should be equal to about $0.8 \mathrm{~mA} \mathrm{~cm}{ }^{-2}$ ); however, it was as high as $1.295 \mathrm{~mA} \mathrm{~cm}^{-2}$. Meanwhile, it was found that the rate of electron transfer during ACAP oxidation at the potential of the peak maximum on the $\mathrm{Au} / \mathrm{NPs}-\mathrm{Au}$ electrode was about 3.5 fold faster, relative to that on the unmodified Au electrode. This means that besides the increase in the real area of the electrode surface as a result of its coverage with DHLA, CA and NPs-Au during the modification process, another effect must also contribute to the very high $j_{\mathrm{p}}$ value attained at the Au/NPs-Au electrode. It is worth emphasizing that such high $j_{\mathrm{p}}$ values corresponding to ACAP oxidation may indicate the presence of specific interactions of its molecules with the electrode modified with an SAM layer. Such interactions would decrease the energy barrier for the oxidative electron transfer. ${ }^{48,51}$ Moreover, as previously reported, sulfur-containing aliphatic carboxylic acids form well-organized monolayers on the bare gold electrode. ${ }^{52,53}$ Most probably, such a structure ensures the easier migration of reactants through the alkane chains to the electrode surface. This opinion is supported by the observation that the permeability of SAMs increases with higher levels of substrate roughness, ${ }^{54}$ which was confirmed by infrared reflection-absorption spectroscopy data. ${ }^{55}$ Nevertheless, the SAM layer effectively protects the metal surface against adsorption of reaction products which poisons the electrode surface. The gold nanoparticles immobilized on the outer side of the SAM Au/DHLA/CA layer attached to the gold surface facilitate accumulation of the substance studied at the electrode/solution interface and efficiently promote tunneling of electrons between the substance analyzed and the electrode surface. ${ }^{56}$ Thus, modification of the surface electrode not only increases the real electrode surface area but also facilitates charge transfer between the oxidized compound and the gold electrode.

\section{Effect of solution $\mathrm{pH}$ and the potential scan rate on the current response of ACAP electrooxidation}

From the obtained set of cyclic voltammograms it was found that the potential of the anodic current peaks attributed to the quasi-reversible oxidation of ACAP to ACAP-quinone shifted towards lower (i.e. less positive values) electrode potentials with an increase in the $\mathrm{pH}$ of the investigated solution, as shown in Fig. 4a. According to Fig. $4 \mathrm{~b}$, with an increase in $\mathrm{pH}$, the peak potential is negatively shifted. Analysis of the variation of the peak potential $E_{\mathrm{p}}$ with $\mathrm{pH}$ of the supporting electrolyte confirms that during the electrode process not only electrons but also protons are released from the ACAP molecules. The linear regression (in the $\mathrm{pH}$ range of 2 to 10) provides a slope of $0.060 \pm 0.001 \mathrm{~V}\left(R^{2}=0.998, n=10\right)$ per unit $\mathrm{pH}$. The magnitude of the $\mathrm{d} E_{\mathrm{p}} / \mathrm{dpH}$ slope is very close to the theoretical Nernstian value of $0.059 \mathrm{~V}$ and indicates that the number of protons and electrons involved in the oxidation mechanism is the same. ${ }^{48}$ Furthermore, analysis of the CVs reveals the influence of the a)

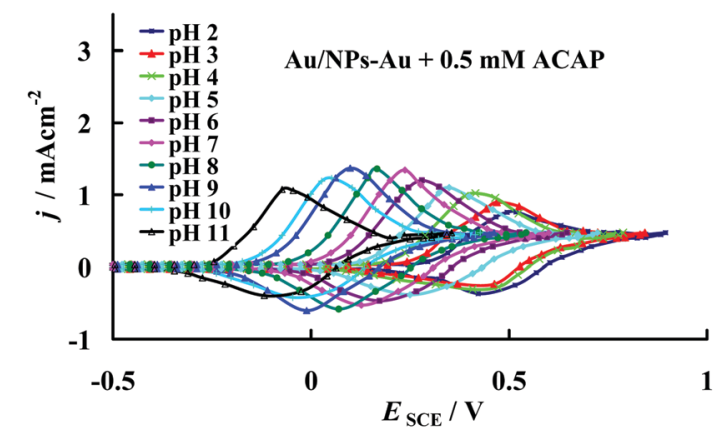

b)

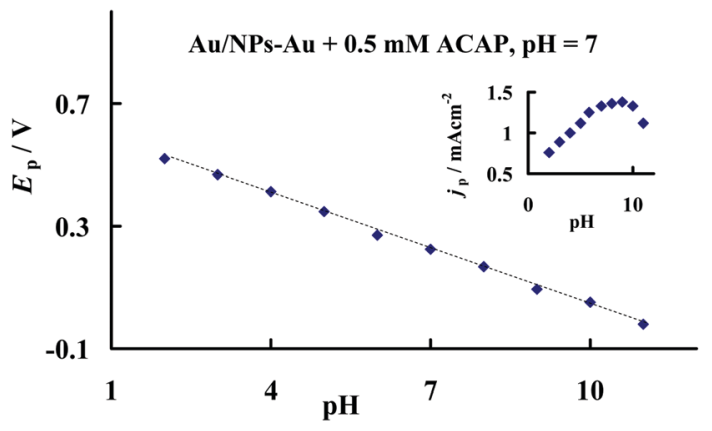

c)

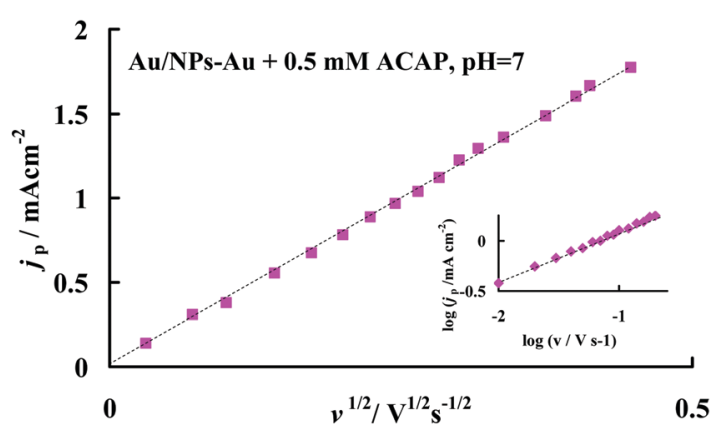

Fig. 4 (a) CVs of the Au/NPs-Au electrode recorded in solutions at different $\mathrm{pH}$ with $0.5 \mathrm{mM} \mathrm{ACAP}, v=0.1 \mathrm{~V} \mathrm{~s}^{-1}$. (b) Effect of $\mathrm{pH}$ on the current peak potential for $0.5 \mathrm{mM} \mathrm{ACAP}$ at Au/NPs-Au, $v=0.1 \mathrm{~V} \mathrm{~s}^{-1}$. Inset: Effect of $\mathrm{pH}$ on the current peak density for $0.5 \mathrm{mM} \mathrm{ACAP}$ at Au/NPs-Au, $v=0.1 \mathrm{~V} \mathrm{~s}^{-1}$. (c) Dependence of the current peak density on the square root of potential scan rate for the oxidation of $0.5 \mathrm{mM} \mathrm{ACAP}$ at the $\mathrm{Au} / \mathrm{NPs}-\mathrm{Au}$ electrode. Inset: Dependence of the current peak density on potential scan rate in double logarithm coordinates for the oxidation of 0.5 mM ACAP at the Au/NPs-Au electrode.

solution $\mathrm{pH}$ on the current peak density $\left(j_{\mathrm{p}}\right)$. Maximum current densities were obtained in the pH range between 6 and 9 (see inset in Fig. 4b). However, taking into account the prospective practical application of the modified gold electrode as a sensor in physiological systems, all subsequent experiments were carried out in a buffer solution of $\mathrm{pH} 7$.

Scan rate is one of the parameters that significantly affects the electrooxidation of various compounds. In the present study, it was observed that the oxidation peak potentials shift positively with an increase in potential sweep rate. A linear 
relationship between the current peak density $\left(j_{\mathrm{p}}\right)$ corresponding to ACAP oxidation and the square root of the scan rate $\left(v^{1 / 2}\right)$ in the buffer solution of $\mathrm{pH} 7$ was obtained for a scan rate in the range of $v=0.001 \mathrm{~V} \mathrm{~s}^{-1}$ to $v=0.2 \mathrm{~V} \mathrm{~s}^{-1}$ (Fig. 4c). Analysis of the obtained data using linear regression reveals the slope of $\mathrm{d} \log \left(j_{\mathrm{p}}\left[\mathrm{mA} \mathrm{cm}^{-2}\right]\right) /$ $\mathrm{d} \log \left(v\left[\mathrm{~V} \mathrm{~s}^{-1}\right]\right)=0.514 \pm 0.02\left(R^{2} \geq 0.998 ; n=15\right)$, (inset in Fig. $\left.4 \mathrm{c}\right)$. From a kinetic point of view, for a purely diffusion controlled process the value of the latter slope should be 0.5 , whereas for a purely adsorption controlled process it should be $1 .{ }^{48}$ Accordingly, the overall rate of ACAP oxidation at the potential of peak maximum under the applied experimental conditions is limited by the diffusion being slower than both the adsorption of ACAP and the following charge transfer at the electrode/solution interface. This relation is favorable for the quantitative determination of ACAP concentration in electrolyte solutions.

\section{Quantitative analysis of ACAP electrooxidation}

As mentioned above, in the evaluation of the catalytic effect of different electrodes on the electrooxidation process, a decrease in the overpotential of oxidation and an increase in the current density should be considered. Without a doubt, the modified electrode prepared in this work simultaneously satisfies both conditions, thus it appears to be straightforward for analytical application. Since ACAP plays an important role in human life, its accurate quantitative determination is very important. However, as shown in Fig. 5a, precise detection of ACAP on the bare gold electrode is practically impossible in samples containing interfering biogenic compounds such as AA and UA. At the unmodified $\mathrm{Au}$ electrode the peak potential separations between ACAP and AA, ACAP and UA and AA and UA are $\Delta E_{\mathrm{ACAP}-\mathrm{AA}}=0.03 \mathrm{~V}, \Delta E_{\mathrm{ACAP}-\mathrm{UA}}=0.05 \mathrm{~V}$ and $\Delta E_{\mathrm{AA}-\mathrm{UA}}=0.08 \mathrm{~V}$, respectively, which show that cyclic voltammetric responses of these compounds overlap. This problem disappeared when the gold electrode modified with SAM layers composed of DHLA, $\mathrm{CA}$ and NPs-Au prepared in this work was used. It is evident from the CVs in Fig. $5 \mathrm{~b}$ that the current peaks corresponding to the oxidation of the mentioned compounds coexisting in a buffer solution of $\mathrm{pH} 7$ are clearly separated from each other. When the Au/NPs-Au electrode is applied in the analysis of a ternary mixture containing ACAP, AA and UA, the peak potential separations between ACAP, AA and UA significantly increase and reach the values of $\Delta E_{\mathrm{ACAP}-\mathrm{AA}}=0.37 \mathrm{~V} ; \Delta E_{\mathrm{ACAP}-\mathrm{UA}}=$ $0.45 \mathrm{~V}$ and $\Delta E_{\mathrm{AA}-\mathrm{UA}}=0.82 \mathrm{~V}$, respectively. Since the gold nanoparticles used herein are stabilized by citrate ions and thus target a negative charge, ${ }^{57,58}$ it seems reasonable to conclude that their chemisorption on the top of the prepared SAM layers leads to a SAM matrix with an excess of negative charge. Thus, the electrode surface covered with the prepared SAM film should repel anionic species through electrostatic repulsion, whereas cationic species should be attracted. Taking into account the values of $\mathrm{p} K_{\mathrm{a}}=9.53, \mathrm{p} K_{\mathrm{a}}=4.1$ and $\mathrm{p} K_{\mathrm{a}}=5.4$ for ACAP, AA and UA, respectively, ${ }^{45}$ the respective potential shift of the ACAP, AA and UA peak currents may be attributed to the electrostatic attraction and repulsion of ACAP and both AA and UA, respectively, and the negatively charged SAM modified layer.
Information on the detection sensitivity of the new Au/NPs-Au modified electrode toward the simultaneous and/or individual determination of ACAP, AA and UA comes from experiments performed with differential pulse voltammetry by changing the concentration of one compound and keeping the concentration of the other two constant. Fig. 5(c-e) display the respective DPV responses of the Au/NPs-Au electrode. The studied ACAP concentration range was from $0.0001 \mathrm{mM}$ to $10 \mathrm{mM}$, whereas the concentrations of $\mathrm{AA}$ and UA were varied from $0.5 \mathrm{mM}$ to $100 \mathrm{mM}$. Analysis of DPVs reveals that the current peak density $\left(j_{\mathrm{p}}\right)$ corresponding to the electrooxidation of ACAP to ACAPquinone is proportional to its concentration $\left(c_{\mathrm{ACAP}}\right)$ over the range of $0.0001 \mathrm{mM}$ to $2 \mathrm{mM}$ at the modified gold electrode, as seen in Fig. 5f. It is worth noting that at the same time, a proportional increase in $j_{\mathrm{p}}$ with an increase in concentration of the analyzed compound was observed for the current peak assigned both to AA and UA oxidation in the whole concentration range applied (Fig. $5 \mathrm{~g}$ and $\mathrm{h}$ ).

The respective linear regression equations obtained with the correlation coefficient $R^{2}$ near 1 are given in Table 1 . Moreover, the detection limits $\left(c_{\mathrm{L}}\right)$ of the compounds investigated, which are estimated according to the formula recommended by IUPAC: $c_{\mathrm{L}}=3 s_{\mathrm{b}} / S^{59}$ (where, $s_{\mathrm{b}}$ is the standard deviation of the current density of the supporting electrolyte solution, $S$ is the slope of the linear $j_{\mathrm{p}}-c_{\mathrm{ACAP}}, j_{\mathrm{p}}-c_{\mathrm{AA}}$ or $j_{\mathrm{p}}-c_{\mathrm{UA}}$ dependences), are included in Table 1. It should be emphasized that the lower the detection limit, the lower the analyzed substance concentration that can be detected. There is no doubt that the modified electrode is suitable for the precise determination of ACAP concentration without any interference of AA and UA. For comparison of the $c_{\mathrm{L}}$ value obtained with the electrode proposed in this work with that estimated for other modified electrodes see the data summary presented elsewhere. ${ }^{21}$ From this summary it is evident that the detection limit of ACAP is lower for the Au/NPs-Au electrode used in the present study compared with that found for many other modified electrodes (except the glassy carbon electrode modified with polycalconcarboxylic acid ${ }^{23}$ ). Most probably the architecture with the gold nanoparticles, which are covalently immobilized on the top side of the self-assembled Au/DHLA/CA layer obtained herein, promotes the accumulation of ACAP at the electrode/solution interface and the gold nanoparticles act as electron antennae, efficiently tunneling electrons between the solute and the electrode and this contributes to the increase in the electrode sensitivity toward ACAP detection. ${ }^{56}$ It should be highlighted that on the Au/NPs-Au electrode, the ACAP concentration range in which the linear relationship of $j_{\mathrm{p}}-c_{\mathrm{ACAP}}$ is fulfilled is wider than that obtained for other modified electrodes. ${ }^{21}$

\section{Sample analysis}

In order to test the practical application of the newly prepared voltammetric sensor, samples containing mixtures of ACAP, AA and UA, which were prepared as described in the Experimental section, were examined electrochemically via DPV and then the concentrations of ACAP, AA and UA were estimated using the calibration method. ${ }^{60}$ All the measurements were repeated five 
a)

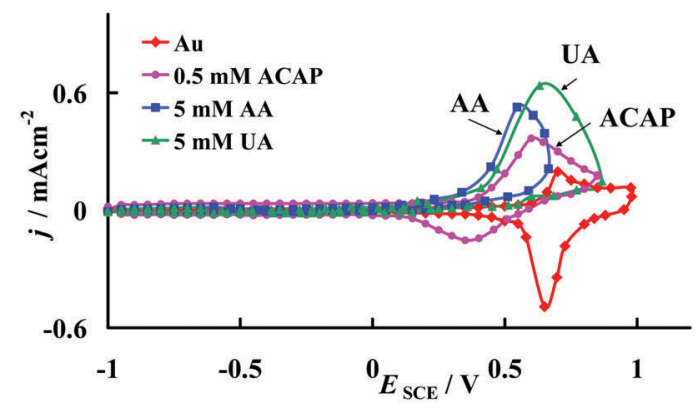

c)

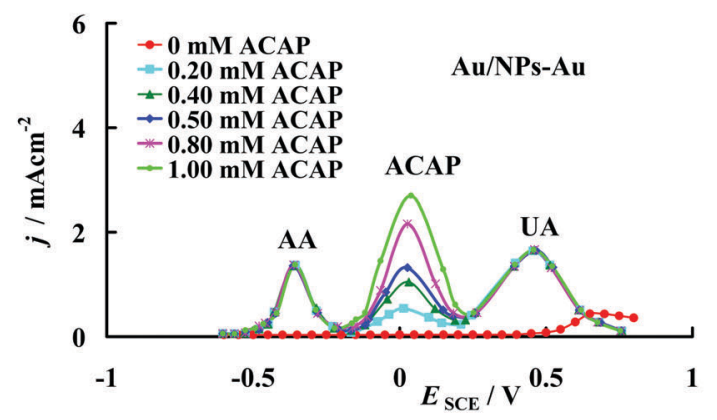

d)

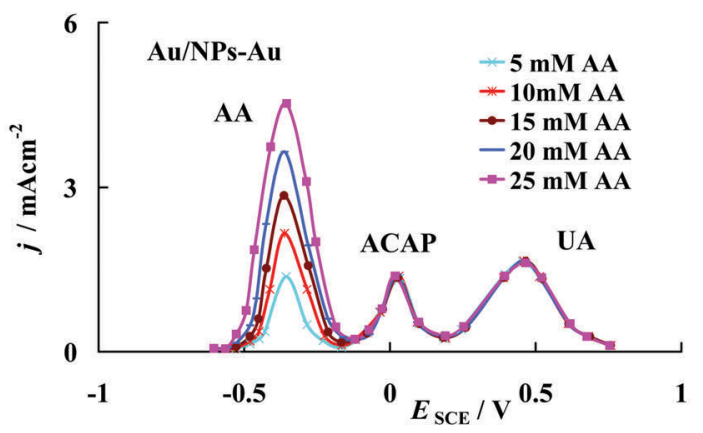

e)

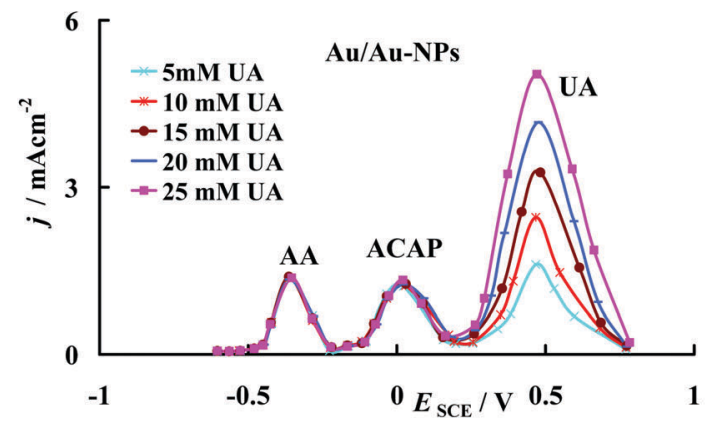

b)

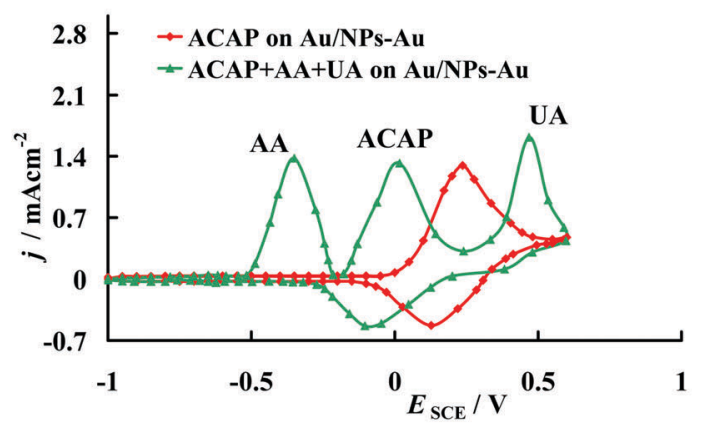

f)

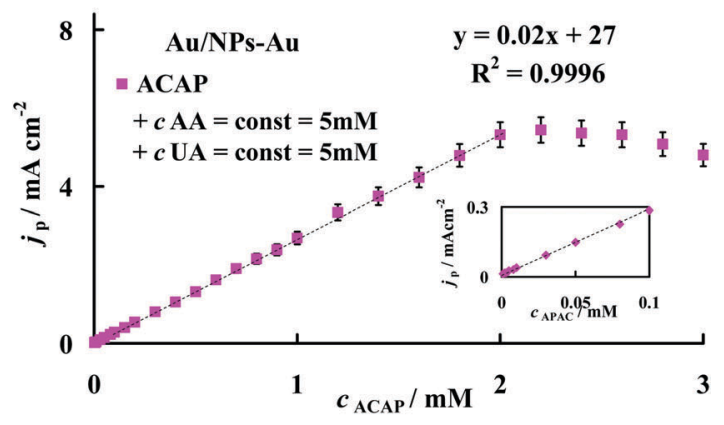

g)

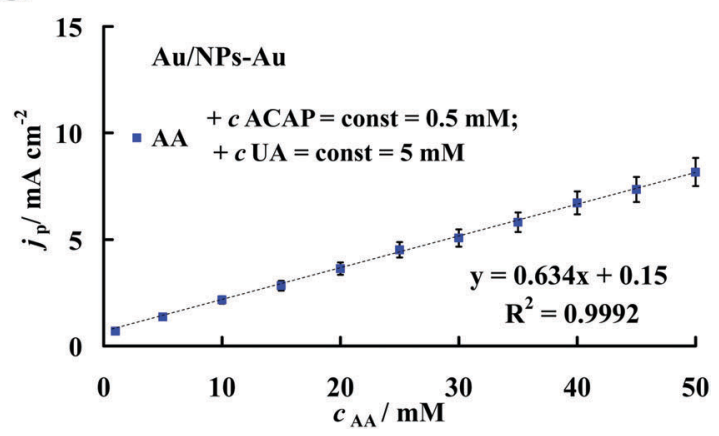

h)

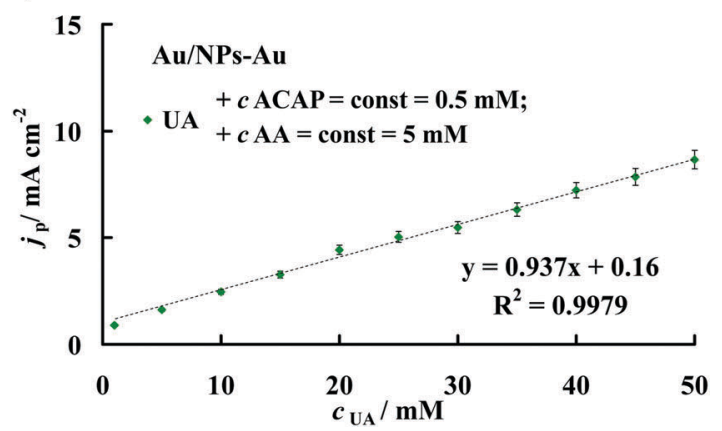

Fig. $5 \mathrm{CVs}$ of (a) Au and (b) Au/NPs-Au electrodes in $60 \mathrm{mM}$ phosphate buffer, pH $=7$ with $0.5 \mathrm{mM} \mathrm{ACAP}+5 \mathrm{mM} \mathrm{AA}+5 \mathrm{mM} \cup \mathrm{A} . v=0.1 \mathrm{~V} \mathrm{~s}{ }^{-1}$. (c-e) DPVs (amplitude $50 \mathrm{mV}$; pulse width $100 \mathrm{~ms}$; pulse period $200 \mathrm{~ms}$ ), $v=0.1 \mathrm{~V} \mathrm{~s}{ }^{-1}$ recorded at Au/NPs-Au electrode in $60 \mathrm{mM}$ phosphate buffer, pH 7 with (c) $5 \mathrm{mM} \mathrm{AA}+5 \mathrm{mM} \cup \mathrm{A}$ and different concentrations of ACAP; (d) with $5 \mathrm{mM} \mathrm{ACAP}+5 \mathrm{mM} \cup \mathrm{A}$ and different concentrations of AA and (e) with $5 \mathrm{mM}$ $A C A P+5 m M ~ A A$ and different concentrations of UA. ( $f-h)$ Current peak density versus: (f) different concentrations of ACAP with the addition of 5 mM $\mathrm{AA}+5 \mathrm{mM}$ UA. Inset: The same as in the main panel for ACAP concentration range from $0.0001 \mathrm{mM}$ to $0.1 \mathrm{mM}$; (g) different concentrations of AA with the addition of $0.5 \mathrm{mM} \mathrm{ACAP}+5 \mathrm{mM} \cup \mathrm{A}$ and $(\mathrm{h})$ different concentrations of $\mathrm{UA}$ with the addition of $0.5 \mathrm{mM} \mathrm{ACAP}+5 \mathrm{mM} \mathrm{AA}$ in $60 \mathrm{mM}$ phosphate buffer, $\mathrm{pH} 7$ for the Au/NPs-Au electrode, $v=0.1 \mathrm{~V} \mathrm{~s}^{-1}$. 
Table 1 Linear regression parameters and detection limits for the determination of ACAP, AA and UA on the Au/NPs-Au electrode, $v=0.1 \vee s^{-1}$

\begin{tabular}{llll}
\hline Compound & Regression equation & $R^{2}(n)$ & Detection limit $c_{\mathrm{L}} / \mathrm{mM} ;\left(c_{\mathrm{L}} / \mu \mathrm{M}\right)$ \\
\hline ACAP & $j_{\mathrm{p}}\left[\mathrm{mA} \mathrm{cm}^{-2}\right]=(20 \pm 3) 10^{-3}+(270 \pm 2) \times 10^{-1} c_{\mathrm{ACAP}}[\mathrm{mM}]$ & $0.9996(25)(n=18)$ & $1.8 \times 10^{-5}(0.018 \mu \mathrm{M})$ \\
$\mathrm{AA}$ & $j_{\mathrm{p}}\left[\mathrm{mA} \mathrm{cm} \mathrm{cm}^{-2}\right]=(634 \pm 7) 10^{-3}+(150 \pm 6) \times 10^{-3} c_{\mathrm{AA}}[\mathrm{mM}]$ & $0.9992(11)(n=10)$ & $7.7 \times 10^{-2}(77 \mu \mathrm{M})$ \\
$\mathrm{UA}$ & $\left.j_{\mathrm{p}}[\mathrm{mA} \mathrm{cm})^{-2}\right]=(937 \pm 9) 10^{-3}+(160 \pm 6) \times 10^{-3} c_{\mathrm{UA}}[\mathrm{mM}]$ & $0.9979(11)(n=10)$ & $8.6 \times 10^{-2}(86 \mu \mathrm{M})$
\end{tabular}

Table 2 Determination results of ACAP, AA and UA in prepared samples on the Au/NPs-Au electrode, $v=0.1 \mathrm{~V} \mathrm{~s}^{-1}$

\begin{tabular}{|c|c|c|c|c|c|c|}
\hline $\begin{array}{l}\text { Sample } \\
\text { number }\end{array}$ & $\begin{array}{l}\text { Nominal content } \\
\text { of ACAP }(\mathrm{mM})\end{array}$ & $\begin{array}{l}\text { Nominal content } \\
\text { of AA (mM) }\end{array}$ & $\begin{array}{l}\text { Nominal content } \\
\text { of UA }(\mathrm{mM})\end{array}$ & $\begin{array}{l}\text { ACAP concentration } \\
\text { fund }(\mathrm{mM})\end{array}$ & $\begin{array}{l}\text { AA concentration } \\
\text { fund }(\mathrm{mM})\end{array}$ & $\begin{array}{l}\text { UA concentration } \\
\text { fund }(\mathrm{mM})\end{array}$ \\
\hline 1 & 0.066 & 5 & 5 & 0.0655 & 5.12 & 4.87 \\
\hline 2 & 0.066 & 5 & 5 & 0.0668 & 4.96 & 5.18 \\
\hline 3 & 0.066 & 5 & 5 & 0.06650 & 4.98 & 5.04 \\
\hline R.S.D. (\%) & & & & $1.6 \%$ & $2.07 \%$ & $4.0 \%$ \\
\hline Recovery (\%) & & & & $98-102 \%$ & $99-102 \%$ & $97-104 \%$ \\
\hline
\end{tabular}

times for three independent samples under the same experimental conditions. The arithmetical averages of the concentrations of five determinations made for each independent tested sample are listed in Table 2. The relative standard deviations (R.S.D.) together with the recovery ranges of the determination of each compound in the prepared samples are included in Table 2. The statistical parameters show good agreement with the nominal content and indicate that the voltammetric sensor prepared herein could be a promising tool for the simultaneous determination of ACAP, AA and UA in ternary mixtures.

\section{Conclusions}

It has been demonstrated that the rate of ACAP oxidation, which is a compound of great medical importance, is substantially enhanced on the gold surface modified with selfassembled layers composed of dihydrolipoic acid, cysteamine and gold nanoparticles compared to that achieved at a bare gold electrode. The voltammetric sensor prepared exhibits excellent stability and reproducibility. The preparation procedure of the modified electrode is simple and green without the use of toxic solutions, which is important from not only a medical, but also an ecological point of view. The range of ACAP concentration in which its content can be reliably estimated as well as the ACAP detection limit obtained on the modified electrode are sufficient for practical use and thus the obtained modified gold electrode is very promising for application as a sensitive voltammetric ACAP sensor. Moreover, the peak to peak separations obtained on the modified electrode confirm that the newly prepared modified gold electrode appears to be a good candidate for the selective detection and analytical determination of ACAP, AA and UA in ternary mixtures.

\section{Acknowledgements}

The Polish Ministry of Science and Higher Education, Poland is gratefully acknowledged for financial support of this work.

\section{Notes and references}

1 K. E. Barrett, S. M. Barman, S. Boitano and H. L. Brooks, Ganong's review of medical physiology, McGraw-Hille-Book, 2015.

2 M. Mueller, Clinical pharmacology: current topics and case studies, Springer, Vienna, 2008.

3 J. A. M. Pulgarin and L. F. G. Bermejo, Anal. Chim. Acta, 1996, 333, 59-69.

4 M. L. Ramos, J. F. Tyson and D. J. Curran, Anal. Chim. Acta, 1998, 364, 107-116.

5 A. Ruiz-Medina, M. L. Fernandez-deCórdova and M. J. AyoraKañada, Anal. Chim. Acta, 2000, 404, 131-139.

6 V. Rodenas, M. S. Garćia, S. Sánchez-Pedreño and M. I. Albero, Talanta, 2000, 52, 517-523.

7 N. Wangfuengkanagul and O. Chailapakul, J. Pharm. Biomed. Anal., 2002, 28, 841-847.

8 R. M. de Carvalho, R. S. Freire, S. Rath and L. T. Kubota, J. Pharm. Biomed. Anal., 2004, 34, 871-878.

9 J. Meyer and U. Karst, Chromatographia, 2001, 24, 163-167. 10 E. Marin, E. Garcia, A. Garcia and C. Barbas, J. Pharm. Biomed. Anal., 2002, 29, 701-714.

$11 \mathrm{M}$. Li and L. Jing, Electrochim. Acta, 2007, 52, 3250-3257.

12 Q. Wan, X. Wang, F. Yu, X. Wang and N. Yang, J. Appl. Electrochem., 2009, 39, 785-790.

13 Z. A. Alothman, N. Bukhari, S. M. Wabaidur and S. Haider, Sens. Actuators, B, 2010, 146, 314-320.

14 A. Babaei, M. Afrasiabi and M. Babazadeh, Electroanalysis, 2010, 22, 1743-1749.

15 R. Manjunatha, D. H. Nagaraju, G. S. Suresh, J. S. Melo, S. F. D'Souza and T. V. Venkatesha, Electrochim. Acta, 2011, 56, 6619-6627.

16 T.-L. Lu and Y.-C. Tsai, Sens. Actuators, B, 2011, 153, 439-444.

17 A. A. Ensafi, H. Karimi-Maleh, S. Mallakpour and M. Hatami, Sens. Actuators, B, 2011, 155, 464-472.

18 X. Kang, J. Wang, H. Wu, J. Liu, I. A. Aksay and Y. Lin, Talanta, 2010, 81, 754-759.

19 Y. Fan, J.-H. Liu, H.-T. Lu and Q. Zhang, Colloids Surf., B, 2011, 85, 289-292. 
20 H. Filik, G. Çetintaş, A. A. Avan, S. N. Koç and İ. Boz, Int. J. Electrochem. Sci., 2013, 8, 5724-.5737.

21 H. Filik, A. A. Avan, S. Aydar and G. Çetintaş, Int. J. Electrochem. Sci., 2014, 9, 148-160.

22 N. F. Atta, M. F. El-Kady and A. Galal, Sens. Actuators, B, 2009, 141, 566-574.

23 A. L. Liu, K. Wang, W. Chen, F. Gao, Y. S. Chai, X. H. Lin, Y. Z. Chen and X. H. Xia, Electrochim. Acta, 2012, 63, 161-168.

24 M. B. Gholivand and M. Amiri, J. Electroanal. Chem., 2012, 676, 53-59.

25 N. F. Atta, A. Galal and S. M. Azab, Int. J. Electrochem. Sci., 2011, 6, 5082-5096.

26 S. W. Wang, F. Xie and R.-F. Hu, Sens. Actuators, B, 2007, 141, 495-500.

27 A. N. Shipway, E. Katz and I. Willner, ChemPhysChem, 2000, 1, 18-52.

28 S. Kinge, M. Crego-Calama and D. N. Reinhoudt, ChemPhysChem, 2008, 9, 20-42.

29 M. Chirea, Catalysts, 2013, 3, 288-309.

$30 \mathrm{~W}$. Nowicki, The behaviour of systems composed of nanosised particles and very-high-molecular weight linear polymers, Adam Mickiewicz University Press, Poznań, 2002.

31 A. Meier, I. Uhlendorf and D. Meissner, Electrochim. Acta, 1995, 40, 1523-1535.

32 B. Li and Q. Ye, Antifouling surfaces and materials, ed. F. Zhou, Springer, Berlin, Heidelberg, 2014.

33 A. Ulman, Chem. Rev., 1996, 96, 1533-1554.

34 L. Zhang, J. Jia, X. Zou and S. Dong, Electroanalysis, 1996, 16, 1413-1418.

35 T. Łuczak and M. Bełtowska-Brzezinska, Microchim. Acta, 2011, 174, 19-30.

36 C. Retna Raj, T. Okajima and T. Osaka, J. Electroanal. Chem., 2003, 543, 127-157.

37 B. Ballarin, M. C. Cassani, E. Scavetta and D. Tonelli, Electrochim. Acta, 2008, 53, 8034-8044.

38 J. Manso, M. L. Mena, P. Yǎñez-Sedeno and J. Pingarrón, J. Electroanal. Chem., 2007, 303, 1-7.

39 J. McMurry, Organic Chemistry, National Scientific Publishers, Warsaw, 2005.

40 T. Łuczak, Electroanalysis, 2014, 26, 2152-2160.
41 W.-k. Paik, S. Eu, K. Lee, S. Chon and M. Kim, Langmuir, 2000, 16, 10198-10205.

42 S. Chon and W-k. Paik, Phys. Chem. Chem. Phys., 2001, 3, 3405-3410.

43 T. R. Wendland, B. S. Muntean, J. Kaur, J. Mukherjee, J. Chenc, X. Tan, D. Attygalle, R. W. Collins, J. R. Kirchhoff and L. M. V. Tillekeratne, Electroanalysis, 2011, 23, 2275-2279.

44 G. Dodero, L. De Michieli, O. Cavalleri, R. Rolandi, L. Olivieri, A. Dacca and R. Parodi, Colloids Surf., A, 2000, 175, 121-128.

45 www.Reaxys.com.

46 C. Jeyabharathi, P. Ahrens, U. Hasse and F. Scholz, J. Solid State Electrochem., 2016, 20, 3025-3031.

47 R. C. Newman and G. T. Burstein, J. Electroanal. Chem., 1981, 129, 343-348.

48 A. J. Bard and L. K. Faulkner, Electrochemical methods: Fundamentals and applications, Wiley, New York, 2001.

49 S. Trasatti and O. Petrii, Pure Appl. Chem., 1991, 63, 711-734.

50 J. J. Van Benchloten, J. Y. Lewis, W. R. Heineman, D. A. Roston and P. T. Kissinger, J. Chem. Educ., 1983, 60, 772-776.

51 A. Kisza, Electrochemistry II, Technical Scientific Publishers, Warsaw, 2001.

52 S.-F. Liu, X.-H. Li, Y.-C. Li, Y.-F. Li, J.-R. Li and L. Jiang, Electrochim. Acta, 2005, 51, 427-431.

53 J. Zhang and M. Ojama, Electrochem. Commun., 2007, 9, 459-464.

54 M. C. Leopold, J. A. Black and E. F. Bowden, Langmuir, 2002, 18, 978-980.

55 M. O. Finot and M. T. McDermott, J. Electroanal. Chem., 2000, 488, 125-132.

56 L. Wang, J. Bai, P. Huang, H. Wang, L. Zhang and Y. Zhao, Electrochem. Commun., 2006, 8, 1035-1040.

57 Z. Jia, J. Liu and Y. Shen, Electrochem. Commun., 2007, 9, 2739-2743.

58 H. Sellers, A. Ulman, Y. Shnidman and J. E. Eilers, J. Am. Chem. Soc., 1993, 115, 9389-9401.

59 Analytical Methods Committee, Recommendation for definition, estimation and use of the detection limit, Analyst, 1987, 112, 199-204.

60 W. Szczepaniak, Instrumental methods in chemical analysis, Scientific Publishers PWN, Warsaw, 2017. 